\title{
СРАВНИТЕЛЬНЫЙ АНАЛИЗ ПРОСТРАНСТВЕННОГО РАСПРЕДЕЛЕНИЯ ЗАГРЯЗНЁННОСТИ ПОЧВ ТЯЖЕЛЫМИ МЕТАЛЛАМИ И СОСТОЯНИЯ ЭКОСИСТЕМ В ЛОКАЛЬНОЙ ЗОНЕ ВОЗДЕЙСТВИЯ МЕДНО-НИКЕЛЕВОГО ПРЕДПРИЯТИЯ
}

\section{Кашулина Г.М., Литвинова Т.И., Коробейникова Н.М.}

Полярно-альпийский ботанический сад-институт им. Н.А. Аврорина, Апатиты, galina.kashulina@gmail.com

\section{Введение}

Медно-никелевый комбинат «Североникель» (ныне площадка Мончегорск КГМК) на Кольском полуострове, является одним из крупнейших и длительно (более 70 лет) действующих источников выбросов $\mathrm{SO}_{2}$ и тяжелых металлов (TM) на Севере Европы. Первые признаки повреждения растительности северотаежных экосистем в ближайших окрестностях комбината появились сразу же после начала функционирования этого предприятия. По мере увеличения мощностей предприятия зона повреждения экосистем постоянно увеличивалась и к середине 1990-х гг. территория уже в радиусе 15 км от источника выбросов была отнесена к зоне полного повреждения [6]. Однако эта оценка не совсем объективно отражала реальную ситуацию с состоянием экосистем в локальной зоне воздействия комбината «Североникель». Даже в период наивысшего объема выбросов в локальной зоне всегда имелись участки с хорошо сохранившейся растительностью. Одной из целей комплексного почвенно-геоботанического мониторинга, начатого в локальной зоне воздействия в
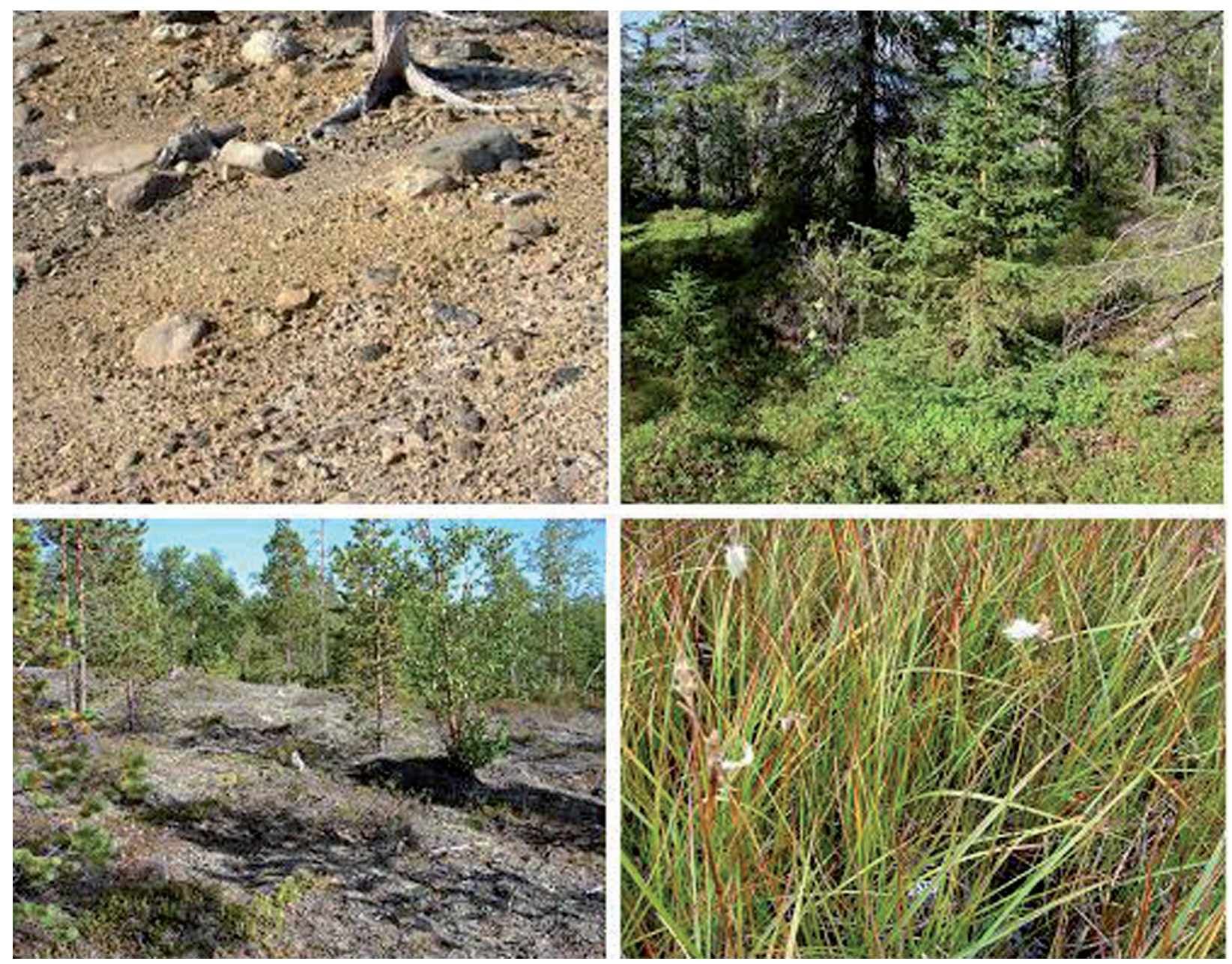

Рис. 1. Различное состояние экосистем в локальной зоне воздействия комбината «Североникель»: полное разрушение с интенсивной почвенной эрозией на пл. IV-1 (верхнее фото слева), умеренное повреждение на пл. V-2 (верхнее фото справа) и II-3 (нижнее фото справа), серьезное на пл. I-1 (нижнее фото слева). 
2001 г. [1, 2, 5] была выявление причины столь широкого варьирования состояния экосистем в пределах локальной зоны: от умеренно поврежденных с выпадением только чувствительных компонентов - мхов и лишайников до техногенных пустошей с интенсивной эрозией почв. Факторами повреждения растений здесь могут быть: прямое токсическое воздействие повышенных концентраций $\mathrm{SO}_{2}$ в воздухе [3], экстремально загрязнённые ТМ атмосферные осадки [5] и почвы [1]. Кроме того, дополнительными стресс-факторами для растений здесь могут быть также: обеднение почв важными питательными элементами [2] и нарушение водного режима экосистем в сторону иссушения [4]. Не смотря на сложность картины, комплексный характер мониторинговых исследований дает возможность выявить влияния некоторых из этих факторов на состояние экосистем в локальной зоне воздействия комбината «Североникель». В данной статье представлен сравнительный анализ пространственного распределения загрязнённости почв токсичными ТМ и состояния экосистем, проведенный на основе результатов комплексного почвенно-геоботанического мониторинга $[1,2,5]$.

\section{материалы и методы}

Площадки мониторинга располагались на разных элемента ландшафта на расстоянии 1-17 км от комбината «Североникель». Каждые 2-3 площадки (арабская цифра через дефис после номера катены) были организованы в геоморфологические или почвенные катены (I-V). Степень загрязнения почв оценивалась по содержанию ТМ в слое 0-3 см верхнего органогенного горизонта почв, который непосредственно контактирует с техногенным потоком и характеризуется высокой способностью аккумулировать ТМ. Отбор проб проводился в 2001, 2002 и с 2005 по 2011 гг. в 20-ых числах августа. Определение $\mathrm{Ni}, \mathrm{Cu}, \mathrm{Co}, \mathrm{Mn}$ проводилось атомно-абсорбционным методом после разложения образца в конц. $\mathrm{HNO}_{3}$. Одновременно на площадках велись наблюдения за химическим составом атмосферных осадков [5].

Состояние экосистем на площадках мониторинга оценивалось по 4-ём градациям: умеренное - отсутствуют только чувствительные компоненты (мхи и лишайники), основные компоненты экосистем угнетены, но их обилие сохраняется на фоновом уровне; серьезное - очень угнетенное состояние деревьев и кустарничков с существенным снижением их обилия; сильное - кустарнички отсутствуют или представлены единичными сильно угнетенными растениями, редкие выжившие угнетенные деревья, интенсивная почвенная эрозия; полное - представляют техногенные пустоши с отсутствием или единичными выжившими, очень угнетенными кустарничками и деревьями, а также интенсивной почвенной эрозией (рис. 1).

\section{Результаты и обсуждение}

Наличие экосистем, сохранивших обилие основных видов растений коренных экосистем на фоновом уровне (лесные горные экосистемы на пл. V-2 и V-3 и все низинные болотные экосистемы на пл. I-3, II-3, III-4, IV-3 и V-4), а также выживание отдельных древесных и кустарничковых растений на площадках с серьезным, сильным и даже полным повреждением экосистем (рис. 1) после 70 лет экстремального загрязнения (концентрации $\mathrm{SO}_{2}$ в воздухе в период наивысшего объема выбросов в десятки тысяч раз превосходили фоновые показатели [3], а современные уровни концентраций Ni в верхнем органогенном горизонте почв превышают фоновые значения до 2000, $\mathrm{Cu}$ - до 700 , приблизившись по концентрации к перерабатываемым рудам [1]) является удивительным фактом. Поскольку только на отдельных площадках корни растений находятся в этом экстремально загрязненном слое (в большинстве случаев растения увели корни в более глубокие, менее загрязненные слои почвы) концентрации ТМ в верхних слоях почв и состояние экосистем нельзя рассматривать как прично-следственные явления для условий локальной зоны. Однако, сопоставимость запасов ТМ в верхнем органогенном горизонте почв с их выпадением за весь период деятельности предприятия позволяют использовать их концентрации в качестве показателя кумулятивного техногенного воздействия на экосистемы [1]. И в этом аспекте сравнительный анализ распределения уровней загрязнения почв ТМ и состояние экосистем вполне правомерен. 

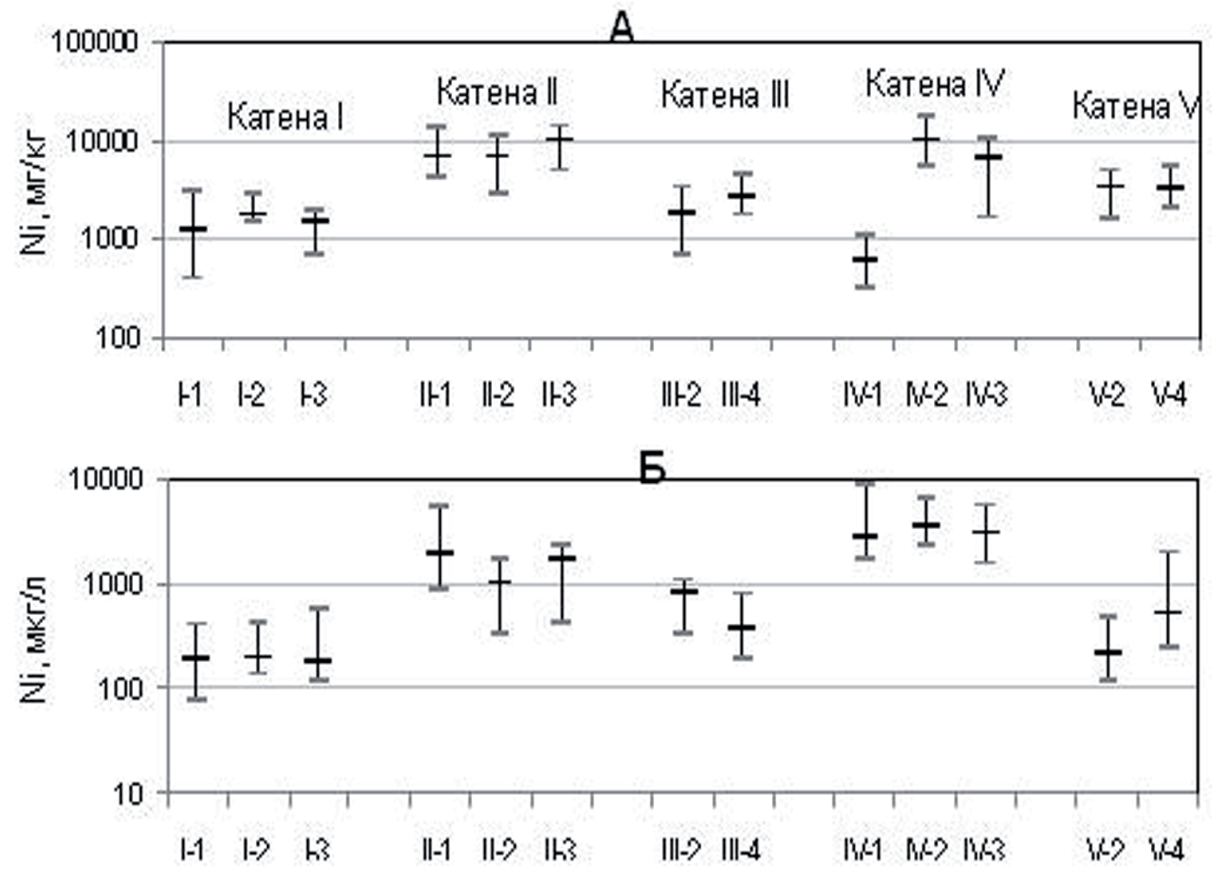

Рис. 2. Медиана и минимум - максимум варьирование концентрации кислоторастворимой формы Ni в слое 0-3 см верхнего органогенного горизонта почв (А), а также общей концентрации Ni в талой снеговой воде (Б) на площадках мониторинга за 2005-2011 гг.

Для оценки влияния удаленности от источника выбросов на уровни концентраций ТМ в верхних слоях почв и состояние экосистем сравнивали площадки, расположенные на вершинах холмов и склонах (пл. I-1, II-1, III-2, IV-2 и V-2). Различия в расположении этих площадок в убывающем ряду по следующим показателям:

- расстояние (км): IV-2 (3, СC3) $=\mathrm{V}-2(3, \mathrm{~B})>\mathrm{II}-1(8, \mathrm{C})>\mathrm{III}-2(8, \mathrm{CC} 3)>\mathrm{I}-1(17, \mathrm{CCB})$;

- концентрации Ni в снеге (рис. 2Б): IV-2>II-1>III-2>V-2>I-1;

- концентрации Ni в почве (рис. 2A): IV-2>II-1>V-2>III-2>I-1;

- повреждение экосистемы: IV-2>>III-2>II-1>I-1>>V-2

свидетельствуют о том, что удаленность площадки от источника выбросов и уровень техногенной нагрузки на ней не всегда определяет уровень загрязнения верхних слоев почв ТМ и состояние экосистемы. Значительно меньшее повреждение экосистемы на пл. V-2 при высоких концентрациях Ni в почве и снеге обусловлены не только ее расположением не по розе ветров, но и лучшими условиями увлажнения за счет близкого уровня грунтовых вод и более высоким уровнем плодородия почвы [2]. Изменение положения пл. III-2 в ряду повреждения экосистем относительно ряда концентраций Ni в снеге и почве, наоборот, обусловлено неблагоприятными природными особенностями места - сухостью и низким уровнем плодородия почвы.

Одной из самых интересных особенностей локальной зоны воздействия комбината «Североникель» является зависимость состояния экосистем от ее положения в ландшафте. Наиболее сильные повреждения растительности были свойственны площадкам, расположенным на повышенных элементах ландшафта (вершины холмов и верхние части склона). В зависимости от удаленности источника выбросов повреждение экосистем на этих площадках варьирует от сильного (пл. II-1, III-2) до полного (пл. IV-1, IV-1, III-1). Растительность на площадках, расположенных у подножий склонов с уровнем грунтовых вод в пределах почвенного профиля характеризуются меньшей степенью повреждения по сравнению с выше расположенными в катене. Например, экосистемы на пл. I-2 и II-2 имели серьезную степень повреждения, в то время как площадки расположенные выше в катенах - пл. I-1 и II-1, соответственно, характеризовались уже сильным повреждением. 
Травянистые растения на всех низинных болотах (пл. I-3, II-3, III-4, IV-3 и V-4) в локальных депрессиях и после 70-летнего воздействия выбросов сохранили свое обилие на фоновом уровне и плодоносили. Их состояние не зависело ни от удаленности источника выбросов, ни от текущей техногенной нагрузки (рис. 2 Б), ни от накопленных экстремальных концентраций ТМ в почвах (рис. 2 А).

Поскольку площадки в пределах одной катены расположены на расстоянии нескольких сотен метров друг от друга, характеризовались близкими современными техногенными концентрациями ТМ в почве, то очевидно, что столь большие различия по состоянию экосистем, занимающих разные позиции в ландшафте не связаны с уровнями загрязнения почв ТМ. Поскольку единственным различием между экосистемами на разных элементах ландшафтах является уровень грунтовых вод относительно корнеобитаемого слоя, можно заключить, что именно лучшие условия увлажнения в подчинённых элементах ландшафта обусловливают значительно более высокую устойчивость сосудистых растений в подчиненных элементах ландшафта к воздействию техногенного фактора, даже при экстремальном его уровне. Эти исследования также подтверждают, ранее высказанную гипотезу [4] о том, что нарушения водного режима экосистем автономных ландшафтов в сторону иссушения в результате гибели чувствительных компонентов - мхов и лишайников (играют большую роль в регулировании водного режима экосистем) могут быть дополнительным стресс-фактором для сосудистых растений в условиях локальной зоны.

\section{Литература}

1. Кашулина Г.М. Экстремальное загрязнение почв выбросами медно-никелевого предприятия на Кольском полуострове // Почвоведение. 2017. № 7. С. 860-873.

2. Кашулина Г.М., Кубрак А.Н., Баскова Л.А., Коробейникова Н.М. Влияние длительного экстремального загрязнения выбросами комбината «Североникель» на содержание доступных для растений $\mathrm{P}, \mathrm{K}, \mathrm{Ca}$ и Мg в подзолах // Вестник МГТУ. Т. 19. №1/2. 2016. С. 184-193.

3. Kashulina G. Reimann C., Banks D. Sulphur in the Arctic environment (3). Environmental impact // Environmental Pollution, 2003. V. 124/1. P. 151-171.

4. Kashulina G., Reimann C., Finne T.E., Halleraker J.H., Ayras M., Chekushin V.A. The state of the ecosystems in the Central Barents Region: scale, factors and mechanism of disturbance // The Science of the Total Environment, 1997. N. 206. P. 203-225.

5. Kashulina G., de Caritat P., Reimann C. Snow and rain chemistry around the "Severonikel" industrial complex, NW Russia: Current status and retrospective analysis // Atmospheric Environment. 2014. V. 89. P. 672-682.

6. Tikkanen E. and Niemela I. Kola Peninsula pollutants and forest ecosystems in Lapland. Finland's Ministry of Agriculture and Forestry, The Finnish Forest Research Institute. Gummerus Kirjapaino Oy Jyvaskyla, 1995. 82 p. 